International Journal of Current Advanced Research

ISSN: O: 2319-6475, ISSN: P: 2319 - 6505, Impact Factor: SJIF: 5.995

Available Online at www.journalijcar.org

Volume 6; Issue 4; April 2017; Page No. 3316-3317

DOI: http://dx.doi.org/10.24327/ijcar.2017.3317.0260

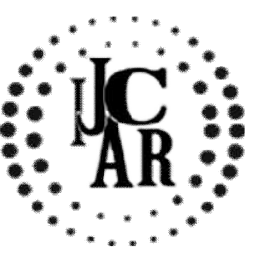

Research Article

\title{
A RELATIONSHIP BETWEEN BODY MASS INDEX AND CHRONIC KIDNEY DISEASE - A SURVEY
}

\author{
Abijeth.B and Merwin.K.Soman
}

Saveetha Medical College \& A Hospitals, 162, P.H.Road, Chennai - 600077

\section{A R R T I C L L E I N F O}

\section{Article History:}

Received $19^{\text {th }}$ January, 2017

Received in revised form $5^{\text {th }}$ February, 2017

Accepted $12^{\text {th }}$ March, 2017

Published online $28^{\text {th }}$ April, 2017

\section{Key words:}

Body mass index and chronic

Kidney disease

\begin{abstract}
A B S T R A C T
Aim: To find the relationship body mass index (BMI) to Chronic Kidney Disease

Objective: To explore the relationship of Body mass index and the prevalence of Chronic

Kidney Disease. And also to improve the early evaluation and management of risk factors associated with it.

Background: Overweight and obesity have become global epidemics and it has been suggested that they can lead to impaired kidney function.An increase in body fat is often associated with an increased risk of the metabolic diseases such as chronic kidney disease, diabetes mellitus, hypertension and dyslipidemia . Body mass index is the primary focus of any obesity treatment. The relationship between the body weight and metabolic diseases helps in a better understanding of the pathophysiological process.

Reason: To help improved evaluation and management of risk factors associated with Chronic Kidney Disease.
\end{abstract}

Copyright $₫ 2017$ Abijeth.B and Merwin.K.Soman. This is an open access article distributed under the Creative Commons Attribution License, which permits unrestricted use, distribution, and reproduction in any medium, provided the original work is properly cited.

\section{INTRODUCTION}

Obesity defined by elevated body mass index (BMI) has been regarded as a cardiovascular risk factor in the general population. Obesity is also associated with increased risk of incident Chronic kidney disease. ${ }^{[1-9]}$ Negative effects of obesity include those effects mediated by conditions caused or worsened by it, such as diabetes mellitus (DM) or hypertension, and direct adverse metabolic effects, such as inflammation, increased synthesis of apolipoprotein B and very LDLs, increased production of insulin, and insulin resistance. ${ }^{[10]}$

The deleterious effects of obesity on human health are systemic in nature, and kidney dysfunction is now recognized as a relevant health risk posed by obesity. Diabetes and hypertension are established pathways whereby fat excess may induce renal damage but the risk for chronic kidney disease (CKD) in obesity is largely independent of these comorbidities. $^{[11]}$ Several population-based, observational studies showed obesity, defined by BMI, as an independent risk factor in the development of CKD and end stage kidney disease(ESKD). In other studies overweight, obesity and increased central fat distribution have been associated with reduced estimated glomerular filtration rate (eGFR)and microal buminuria. The most widely recognized strategy for characterizing obesity depends on BMI

*Corresponding author: Abijeth.B

Saveetha Medical College \& A Hospitals, 162, P.H.Road,

Chennai - 600077
(WHO) considers a BMI in the vicinity of 20 and $25 \mathrm{~kg} / \mathrm{m} 2$ as ordinary weight, a BMI in the vicinity of 25 and $30 \mathrm{~kg} / \mathrm{m} 2$ as overweight, and a BMI of $>30 \mathrm{~kg} / \mathrm{m} 2$ as fat. It should be emphasized that population norms of BMI could be different based on ethnic and racial background. ${ }^{[12]}$ Although BMI is easy to calculate and used in many nutritional guidelines, this metric is a poor estimate of fat mass distribution, especially in CKD. ${ }^{[13]}$

\section{MATERIALS AND METHODS}

The study included a sample of 50 patient who were admitted in the inpatient ward of general medicine department in Saveetha medical college \& Hospitals. The Height and weight of 50patients who were diagnosed as chronic kidney disease were recorded and their respective BMI were calculated. The calculated BMI was then analyzed statistically.

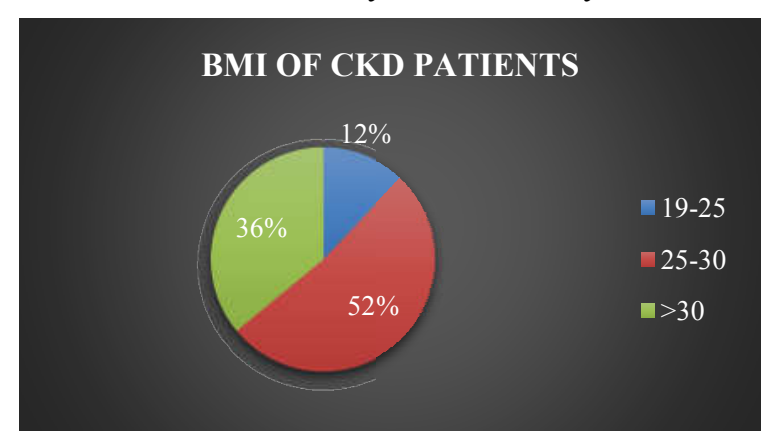

Figure 1 


\section{RESULTS}

The recorded data were statistically analyzed and the results were formulated. According to the survey among the chronic kidney disease patients, $52 \%$ of the patients were present in the category of $25-30$ BMI whereas $36 \%$ of the patients were present in the category of above 30BMI. $12 \%$ of the patients were present in the category of 19-25BMI. (Fig 1)(Fig 2)

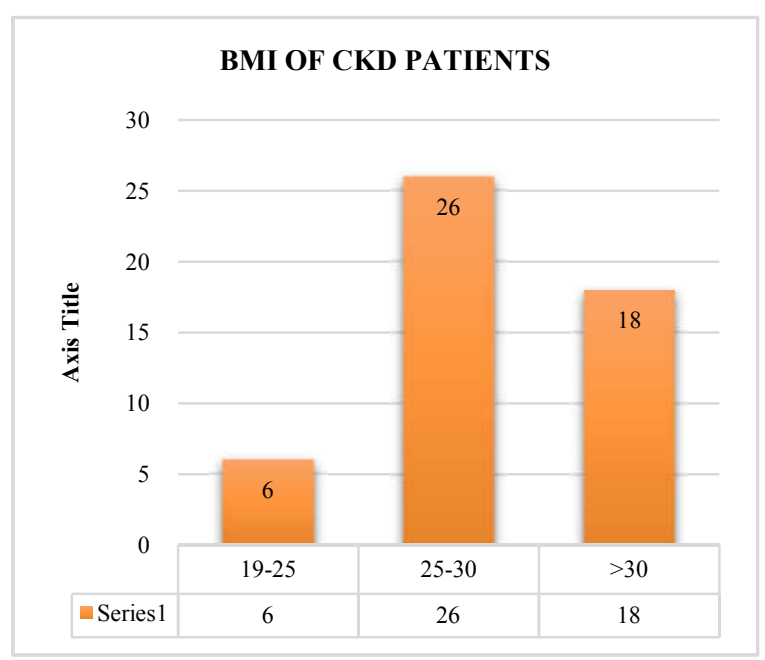

Figure 2

\section{DISCUSSION}

Few studies have evaluated BMI as a potential risk factor in the development of kidney disease, and available results are in favor for it. Similarly, studies of BMI and CKD showed variable results, depending on study design and method of measuring. Also, the exact role of increased body size in the development of CKD independent of confounding factors is unclear. In a cross-sectional analysis, morbid obesity was related to $\mathrm{CKD}$, but these associations were mediated by the effects of diabetes and hypertension. The studies of Beddhu et al. ${ }^{[14]}$ demonstrated that the survival advantage of high BMI among CKD patients on long-term dialysis was limited to those with normal or increased muscle mass. Patients with high BMI and high body fat had increased all-cause and cardiovascular mortality.

Pathophysiological studies have revealed that, among patients with CKD, obesity is not an innocuous bystander and may directly or indirectly damage the kidney.Evidence for the direct damaging effect of obesity is the following. Because of heightened sympathetic activity, high levels of angiotensin II, and hyperinsulinemia, obesity is often accompanied by glomerular hyperfiltration and increased proximal tubular sodium resorption. Enhanced proximal salt reabsorption determines a reduced delivery of sodium to the macula densa. This then causes afferent vasodilatation and enhanced renin synthesis. As a result of high local angiotensin II levels, the efferent arteriole is constricted in the obese, and glomerulomegaly and focal glomerulosclerosis ensue. Evidence is emerging that fat cells may trigger inflammation in the kidney indirectly by producing inflammatory cytokines, which may further aggravate renal dysfunction. ${ }^{[15]}$

\section{CONCLUSION}

In conclusion, our study has apparently shown a significant association between BMI and CKD, independent of other potential mediators such as hypertension, diabetes, high cholesterol level and insulin resistance. Further analyses are necessary to confirm the pathogenesis of obesity-related CKD.

\section{References}

1. DawberTR, MeadorsGF, MooreFEJr.: Epidemiological approaches to heart disease: The Framingham Study. Am J Public Health Nations Health 41: 279-281, 1951

2. Kannel WB, Feinleib M, McNamara PM, Garrison RJ, Castelli WP: An investigation of coronary heart disease in families. The Framingham offspring study. Am J Epidemiol 110: 281-290, 1979

3. Calle EE, Thun MJ, Petrelli JM, Rodriguez C, Heath CW Jr.: Body-mass index and mortality in a prospective cohort of U.S. adults. N Engl J Med 341: 1097-1105, 1999

4. Cornoni-Huntley JC, Harris TB, Everett DF, Albanes D, Micozzi MS, Miles TP, Feldman JJ: An overview of body weight of older persons, including the impact on mortality. The National Health and Nutrition Examination Survey I-Epidemiologic Follow-up Study. JClinEpidemiol 44: 743-753, 1991

5. Foster MC, Hwang SJ, Larson MG, Lichtman JH, Parikh NI, Vasan RS, Levy D, Fox CS: Overweight, obesity, and the development of stage $3 \mathrm{CKD}$ : The Framingham Heart Study. AmJKidneyDis 52: 39-48, 2008

6. Kramer H, Luke A, Bidani A, Cao G, Cooper R, McGee D: Obesity and prevalent and incident CKD: The Hypertension Detection and FollowUp Program. AmJKidneyDis 46: 587-594, 2005

7. FoxCS, LarsonMG, LeipEP, CulletonB, WilsonPW, LevyD: Predictors of new-onset kidney disease in a community-based population. JAMA 291: 844-850, 2004

8. Ejerblad E, Fored CM, Lindblad P, Fryzek J, McLaughlin JK, Nyrén O: Obesity and risk for chronic renal failure. JAAmSocNephro 17: 16951702, 2006

9. Pinto-Sietsma SJ, Navis G, Janssen WM, de Zeeuw D, Gans RO, de Jong PE; PREVEND Study Group: A central body fat distribution is related to renal function impairment, even in lean subjects. Am J Kidney Dis 41: 733-741, 2003

10. Haslam DW, James WP: Obesity. Lancet 366: $1197-$ 1209, 2005

11. Hsu CY, McCulloch CE, Iribarren C et al. Body mass index and risk for end-stage renal disease. Ann Intern Med 2006; 144: 21-28

12. WHO Expert Consultation: Appropriate body-mass index for Asian populations and its implications for policy and intervention strategies. Lancet 363: 157-163, 2004

13. Agarwal R, Bills JE, Light RP: Diagnosing obesity by body mass index in chronic kidney disease: An explanation for the "obesity paradox?" Hypertension 56:893-900,2010

14. Beddhu S, Pappas LM, Ramkumar N, Samore M. Effects of body size and body composition on survival in hemodialysis patients. J AmSoc Nephrol. 2003; 14:23662372.

15. Zoccali C. Overweight, obesity and metabolic alterations in chronic kidney disease. Prilozi. 2009;30:17-31. 